\title{
A new species of Polydiscia (Acari, Prostigmata, Tanaupodidae) with reference to its host: a new species of Deuterosminthurus (Collembola, Symphypleona, Bourletiellidae)
}

\author{
ENRIQUE BAQUERO, MARIA LOURDES MORAZA \& RAFAEL JORDANA \\ Department of Zoology and Ecology, University of Navarra, P.O. Box 177, 31080 Pamplona, Navarra, Spain. \\ ebaquero@unav.es; mlmoraza@unav.es; rjordana@unav.es. \\ Contact author: E. Baquero: Phone: +34948 425600 ext. 6495; Fax: +34 948425649
}

\begin{abstract}
During the sampling campaign to describe the Iberian fauna of Collembola, an undescribed species of the family Bourletiellidae living on Genista hispanica L. was found with parasitic mites. The attached parasitic mites were identified as the larval instar of a new species of Polydiscia, a prostigmatid mite of the family Tanaupodidae Thor, 1935. The genus was previously cited in Austria. The Collembola, Deuterosminthurus bisetosus $\mathbf{s p . ~ n o v , ~ w h i c h ~ w a s ~ f o u n d ~ i n ~ d i s t a n t ~ l o c a l i t i e s ~ o n ~ t h e ~ I b e - ~}$ rian Peninsula, and Polydiscia deuterosminthurus sp. nov., are both here described. Both species were found together on Genista for three consecutive years. The abundant material obtained has allowed us to study both species with SEM (Scanning Electron Microscopy), and show characteristics in greater detail than has been possible with light microscopy.
\end{abstract}

Key words: Parasitic mite, Polydiscia, Tanaupodidae, Collembola, Bourletiellidae, Deuterosminthurus, new species

\section{Introduction}

The Collembola are considered one the most abundant groups of Hexapoda as well as one of the most ancient, their systematics, taxonomy and ecology have been widely worked, but there still many species to describe and autoecological studies to be performed. Acari on Collembola have been reported in a few papers: trombidiid larvae on Entomobrya nivalis (L.) and Salina celebensis Schaeffer (Entomobryidae) (Handschin, 1926), phoretic acarid and saproglyphid hypopi on Sminthurus fuscus (L.) (Sminthuridae) (Waldorf, 1974), Erythrites sp. nr. womersleyi (Southcott, 1946) from two Australian species of the genus Corynephoria (Sminthuridae) (Greenslade \& Southcott 1980), and Cheyletus eruditus (Schr.) on unnamed Collembola in Poland (Haitlinger, 1991). 
The genus Polydiscia was previously only known from a species, P. squamata (two specimens) captured by Methlagl (1928) in a locality close to Vienna (Austria). In this paper we describe a new species of this genus as parasite of a new species of collembolan with repeated and numerous captures. We can say with certainty that this species is a true ectoparasite of a Collembola. The abundance of specimens collected has allowed us to describe both species.

\section{Materials and methods}

The collembolan and mite specimens (Figures 1 and 2) were captured by beating the host plants (Genista hispanica L.) in the regressive plant communities of the Western Pyrenean and the Navarra-Alava series of Quercus humilis in Otazu (Navarra, Spain). Samples were taken in May of 1999, 2000 and 2001. The technique allowed us to capture other arthropods species at the same time. The presence of red coloured mites on the body of the new Collembola was detected in the field, but the parasitism was not confirmed until the sampled material was observed using a stereoscopic microscope in the laboratory. Some specimens were permanently mounted in Hoyer's medium on microscope slides. Species identification was carried out using a compound light microscope.

Some specimens of both species were fixed and processed for scanning electron microscopy (SEM). The fixative consisted of a mixture of methanol, acetic acid and water 2:2:1 (Saito \& Osakabe 1992). After washing, samples were dehydrated through a series of increasing concentrations of ethanol up to $100 \%$. Complete desiccation was achieved by the $\mathrm{CO}_{2}$ critical point technique (CPD). Samples were then coated with a $16 \mathrm{~nm}$ layer of gold using a Emitech K550 sputter-coater and a 'DSM Zeiss 940 A' Scanning Electron Microscope was used for observation.

For Polydiscia all measurements are in micrometers rounded to the nearest whole micrometer. Terminology follows that of Welbourn and Young (1987). Legs were measured from the base of the trochanter to the base of the pretarsal claws.

For Deuterosminthurus chaetotaxy terminology follows, with some modifications, Betsch \& Bretfeld (1991) for abdomen and Nayrolles (1987) for tibiotarsi. For the head we follow de traditional denomination for Poduromorpha (Jordana et al, 1997) adding a new setae clipeal denomination.

\section{Polydiscia deuterosminthurus sp. nov. (Figs 1-13)}

Type-host: Deuterosminthurus bisetosus sp. nov.

Type-locality: SPAIN, Navarra, Otazu (UTM co-ordinates 30TWN993375).

Type-specimens: Holotype (larva) collected ex D. bisetosus sp. nov. from Genista 
hispanica. MZNA00310-01 (mounted, permanent slide), 28 May 1999, E. Baquero and R. Jordana leg. Paratypes: two specimens mounted in permanent slide (MZNA00310-02 and MZNA00310-03), three specimens in ethyl alcohol.
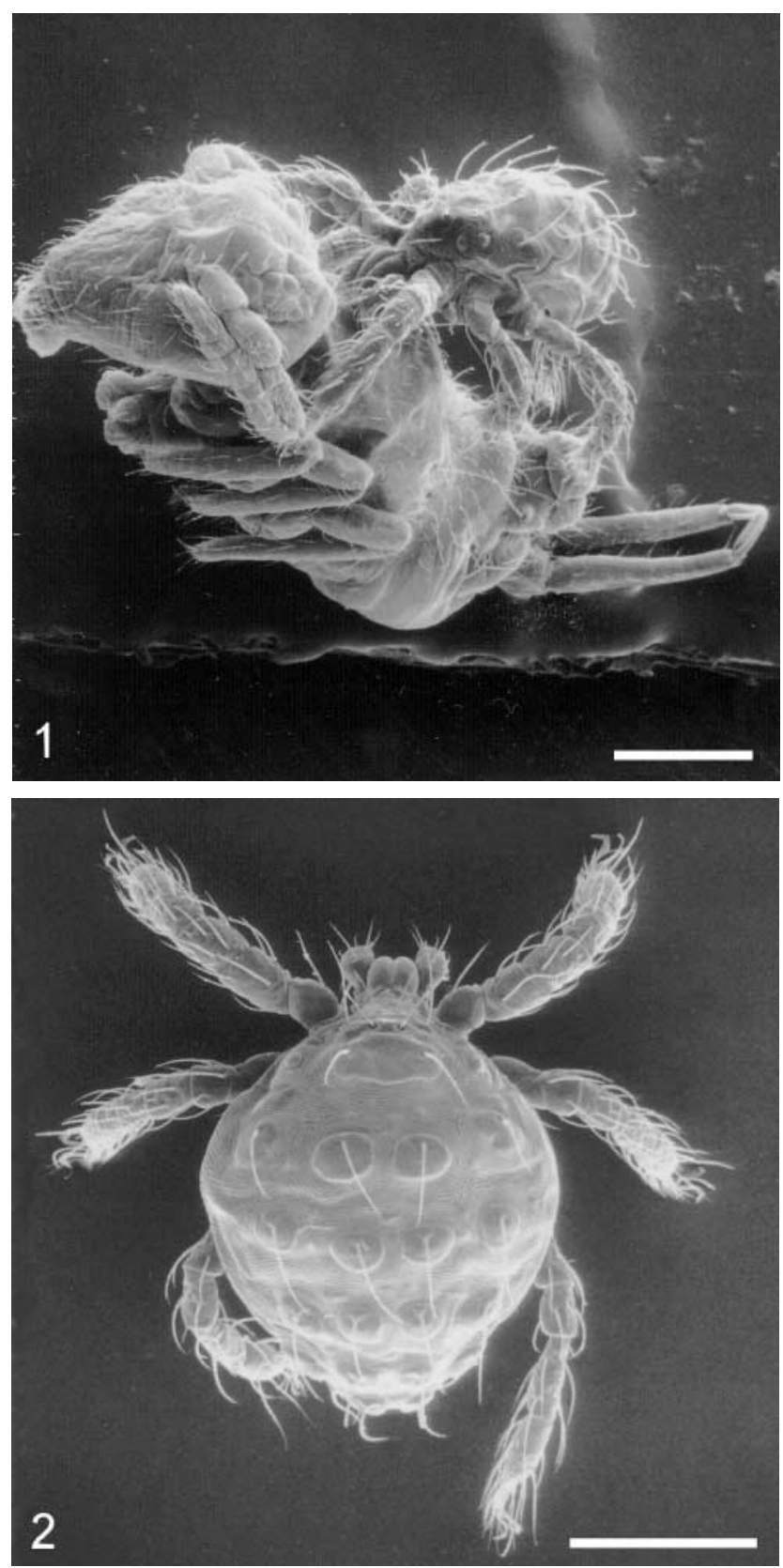

FIGURES 1-2. 1. Deuterosminthurus bisetosus sp. nov. with Polydiscia deuterosminthurus sp. nov. on it. 2. Habitus of Polydiscia deuterosminthurus sp. nov. (Bar: $0.1 \mathrm{~mm}$ ) 
Additional material: Same locality, MZNA00309, 26 May 1999, E. Baquero \& L. Hernández leg. (nine larvae on SEM stub). MZNA00353, 9 May 2000 (three larvae in ethyl alcohol), MZNA00362, 26 May 2000 (eight larvae in ethyl alcohol), MZNA00389, 30 May 2001 (five larvae in ethyl alcohol), E. Baquero and R. Jordana leg.

Zoolog. Inst. Innsbruck (Austria): one slide labelled as 'Polydiscia squamata Trombidiiden - Larve. Leg. et det. Dr. Methlagl. Gaaden b. Wien - TYPE'. Designated 'lectotype' by Vercammen-Grandjean (1972: 237).

Material deposited: MZUN (Museum of Zoology, University of Navarra).

Diagnosis. Larva with the following features: $\mathrm{fD}=4-4-4-4-2=18$; $\mathrm{fV}=2-2$ $2 \mathrm{u}-2=8 ; \mathrm{fnCx}=2-1-2 ; \mathrm{fnTr}=1-1-1 ; \mathrm{fnFe}=6-7-6 ; \mathrm{fnGe}=4-4-4 ; \mathrm{fnTi}=9-$ 9 - 9; fnTa $=25-21-20 ;$ fSol $=\mathrm{I}(0-3-4-1), \mathrm{II}(0-4-2-1)$, III $(0-1-1-0) ; \mathrm{f} \kappa=\mathrm{I}(1$ - 1), II(1 - 0), III(0 - 0); f $\xi=2-2-0$; f $\varepsilon=1-1-0 ; \mathrm{fPp}=0-\mathrm{B}-\mathrm{B}-\mathrm{BNNN}-6 \mathrm{~B} 2 \xi \omega$; Ip $=697$; Tarsus III with developed pretarsus; $\mathrm{fSc}=\mathrm{PL}>\mathrm{S} \geq \mathrm{AL}>\mathrm{AM}$, AP subigual to $\mathrm{AM}, \mathrm{AA}<\mathrm{SB}$.

Description (Figures 1-13). Larva (holotype). Measurements of holotype, the mean, range, and number of other specimens measured in parentheses; when the number is three, the measurements belongs to the paratypes. Colour in life red; white in ethyl alcohol. Idiosoma (Figures 2, 5, 8). Holotype $267 \mu \mathrm{m}$ long (240, 140-290, 25), $205 \mu \mathrm{m}$ wide (160, 120205, 25).

Dorsum: Two eyes similar in size, diameter $9 \mu \mathrm{m}(11,9-11,3)$ on each side of prodorsal sclerite set in an oval sclerite, $29 \mu \mathrm{m}$ long $(29,28-30,3), 15 \mu \mathrm{m}$ wide (11-15, 3), $3 \mu \mathrm{m}$ larger than each eye $(3,3,3)$. Dorsum with nine pairs of weakly barbed setae (Figure 7) ranging in length from $40 \mu \mathrm{m}$ to $47 \mu \mathrm{m}$, all arising from large platelets ranging in size from $20 \times 31 \mu \mathrm{m}$ to $20 \times 28 \mu \mathrm{m}$; cupules $i a$, im, ip and ih present.

Venter: Two pairs of branched sternal setae, $19 \mu \mathrm{m}$ and $15 \mu \mathrm{m}$ respectively, located on their respective coxal field. Three pairs of pseudanal setae: ps $137 \mu \mathrm{m}$ long, ps $236 \mu \mathrm{m}$ long and ps3 $30 \mu \mathrm{m}$ long (Figure 8). Anal sclerite $30 \mu \mathrm{m}$ long $(30,30-32,3)$ by $14 \mu \mathrm{m}$ wide $(13,14-15,3)$ (Figure 8).

Prodorsal sclerite. Shape roughly trapezoidal with anterior and posterior margins convex in the middle region, lateral margins deeply concave, with punctated surface; setae $\mathrm{PL}>\mathrm{S} \geq \mathrm{AL}>\mathrm{AM}$ (AM and SS trichobothridial setae weakly barbed; Figures 5, 9). Measurements of prodorsal sclerite and its setae in Table I.

Gnathosoma (Figures 3, 5-8). Pedipalps: trochanter $18 \mu \mathrm{m}$; femur $10 \mu \mathrm{m}$; genu $13 \mu \mathrm{m}$; palpal tibia-tarsus $16 \mu \mathrm{m}$. Palpal tibia and tarsus fused. Palpal setal formula: 0 - B - B BNNN - 6B2 $\xi \omega$; tibial claw (following to Vercammen-Grandjean, 1972) $24 \mu \mathrm{m}$ long (21, $18-24,3$ ) in apical position, resembling the dorsoapical slightly barbed tarsal eupathidia $\xi$ $22 \mu \mathrm{m}$ long $(22,20-22,3)$. Adoral setae (Figure 6) shorter and wider than pair of subcapitular setae $s c 1$. Chelicera with an oblong shaft, $52 \mu \mathrm{m}$ long $(51,51-52,2)$ by $19 \mu \mathrm{m}$ wide $(18,18-19,2)$; chelostyle $10 \mu \mathrm{m}$ long $(10,9-11,2)$ with a deep longitudinal groove and without teeth (Figure 3). 

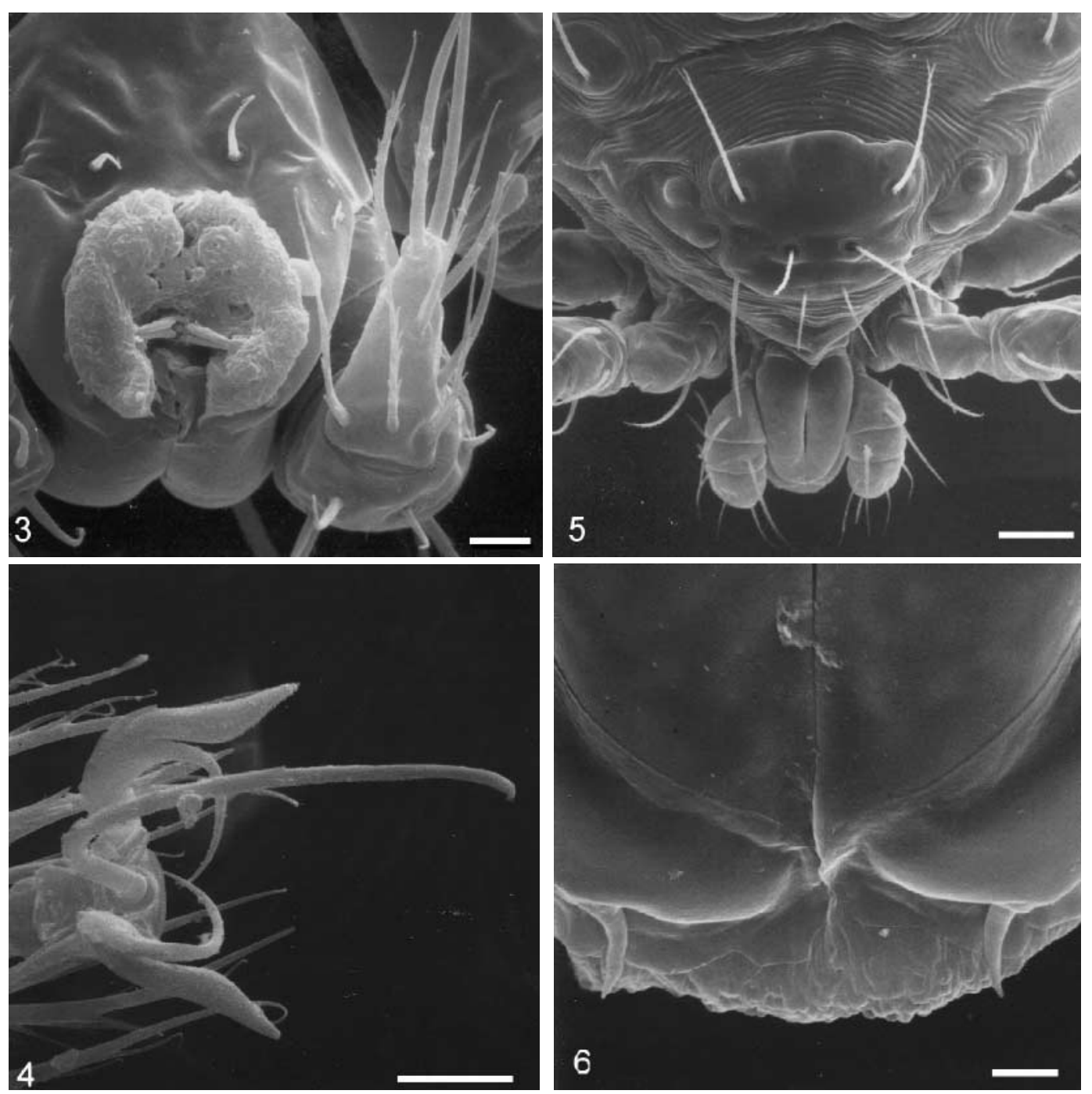

FIGURES 3-6. Polydiscia deuterosminthurus sp. nov. 3. Detail of the gnathosoma, including blade movable digit and palpal tibia-tarsus (Bar: $10 \mu \mathrm{m})$. 4. Detail of pretarsus, sickle-shape empodium and claws, leg I (Bar: $5 \mu \mathrm{m})$. 5. Dorsal view of anterior part of body, gnathosoma and prodorsum (Bar: $20 \mu \mathrm{m})$. 6. Dorsal view of the chelicera apex and adoral setae (Bar: $2 \mu \mathrm{m})$.

Legs (Figures 4 and 11-13). Femora of all legs divided; pretarsi I-III with a thin and curved sickle-shape empodium; paraxial and antiaxial smooth claws with similar shape, divided in two branches: paraxial branch longer, thinner and sharply curved; antiaxial branch foliate and sinuous. Legs I length $245 \mu \mathrm{m}(229,207-245,3)$; coxal field with 2 branched setae (2B); trochanter 1B; basifemur 1B; telofemur 5B; genu 4B, $3 \sigma 22 \mu \mathrm{m}, 1$ microseta $\kappa 4 \mu \mathrm{m}$; tibia 9B, $4 \phi 22 \mu \mathrm{m}, 1 \mathrm{k} 4 \mu \mathrm{m}$; tarsus $1 \omega 27 \mu \mathrm{m}$, 1famulus $\varepsilon 4 \mu \mathrm{m}, 2$ eupathidia with setules ( $\xi \mathrm{h}(=\mathrm{ST} 133 \mu \mathrm{m}, \mathrm{pST} 113 \mu \mathrm{m})$ and $\left.\xi_{\mathrm{p}} 22 \mu \mathrm{m}\right)$ and 25 B. Legs II 
length $219 \mu \mathrm{m}(218,215-219,3)$ : coxal field with 1 branched seta (1B); trochanter 1B; basifemur 2B; telofemur 5B; genu 4B, $1 \sigma 25 \mu \mathrm{m}, 1$ microseta $\kappa 5 \mu \mathrm{m}$; tibia 9B, $2 \phi 19$ $\mu \mathrm{m}$; tarsus $1 \omega$, 1famulus $\varepsilon, 2$ eupathidia with setules ( $\xi \mathrm{h} 29 \mu \mathrm{m}, 7 \mu \mathrm{m}$ and $\xi \mathrm{p} 22 \mu \mathrm{m}$ ) and 21 B. Legs III length $245 \mu \mathrm{m}$ (251, 245-259, 3); coxal field with 2 branched setae (2B); trochanter1B; basifemur 2B; telofemur 4B; genu 4B, $1 \sigma$; tibia 9B, $1 \phi$; tarsus $20 \mathrm{~B}$.

TABLE I. Polydiscia deuterosminthurus sp. nov. Measurements of prodorsal sclerite and its setae.

\begin{tabular}{lcccccccccccc}
\hline & AM & S & AL & PL & AA & SB & AW & PW & ASB & PSB & SD & AP \\
\hline n $^{\circ} 1$ & 29,1 & 43,7 & 39,5 & 47,8 & 10,4 & 14,6 & 45,8 & 41,6 & 25 & 35,4 & 60,3 & 29,1 \\
n$^{\circ} 2$ & 24,9 & 41,6 & 43,7 & 45,8 & 8,32 & 14,6 & 41,6 & 39,5 & 20,8 & 37,4 & 58,2 & 31,2 \\
n'3 & 24,9 & 38,5 & 41,6 & 43,7 & 10,4 & 14,6 & 43,7 & 37,4 & 23,9 & 35,4 & 59,3 & 29,1 \\
mean & $\mathbf{2 6 , 3}$ & $\mathbf{4 1 , 3}$ & $\mathbf{4 1 , 6}$ & $\mathbf{4 5 , 8}$ & $\mathbf{9 , 7 1}$ & $\mathbf{1 4 , 6}$ & $\mathbf{4 3 , 7}$ & $\mathbf{3 9 , 5}$ & $\mathbf{2 3 , 2}$ & $\mathbf{3 6 , 1}$ & $\mathbf{5 9 , 3}$ & $\mathbf{2 9 , 8}$ \\
\hline
\end{tabular}

\begin{tabular}{llllllccccccc} 
PT & 54 & 66 & 38 & 50 & 14 & 15 & 39 & 46 & 27 & 40 & 67 & 33 \\
LT. & 58 & 68 & 40 & 44 & 14 & 18 & 48 & 46 & 28 & 38 & 66 & 33 \\
mean & $\mathbf{5 6}$ & $\mathbf{6 7}$ & $\mathbf{3 9}$ & $\mathbf{4 7}$ & $\mathbf{1 4}$ & $\mathbf{1 6 , 5}$ & $\mathbf{4 3 , 5}$ & $\mathbf{4 6}$ & $\mathbf{2 7 , 5}$ & $\mathbf{3 9}$ & $\mathbf{6 6 , 5}$ & $\mathbf{3 3}$ \\
\hline
\end{tabular}

\begin{tabular}{lcccccccccccc}
\hline & AM/ & PL/S & AM/ & S/AL PL/AL & pa & pm & pp & Ip & T1 & T2 & T3 \\
& S & & AL & & & & & & & & & \\
\hline n$^{\circ} 1$ & 0,67 & 1,1 & 0,74 & 1,11 & 1,21 & 245 & 219,4 & 245,3 & 709,5 & 68,51 & 56,48 & 57,4 \\
n$^{\circ} 2$ & 0,6 & 1,1 & 0,57 & 0,95 & 1,05 & 233 & 218,5 & 248,1 & 700 & 66,66 & 55,55 & 58,33 \\
n$^{\circ} 3$ & 0,65 & 1,14 & 0,6 & 0,93 & 1,05 & 207 & 214,8 & 259,3 & 681,5 & 70,37 & 56,48 & 59,25 \\
mean & $\mathbf{0 , 6 4}$ & $\mathbf{1 , 1 1}$ & $\mathbf{0 , 6 3}$ & $\mathbf{0 , 9 9}$ & $\mathbf{1 , 1}$ & $\mathbf{2 2 9}$ & $\mathbf{2 1 7 , 6}$ & $\mathbf{2 5 0 , 9}$ & $\mathbf{6 9 7}$ & $\mathbf{6 8 , 5 1}$ & $\mathbf{5 6 , 1 7}$ & $\mathbf{5 8 , 3 3}$ \\
\hline & & & & & & & & & & & & \\
PT & 0,82 & 0,76 & 1,42 & 1,74 & 1,32 & 268 & 258 & 274 & 800 & 66 & 64 & 60 \\
LT & 0,85 & 0,65 & 1,45 & 1,7 & 1,1 & 252 & 232 & 258 & 742 & 64 & 63 & 58 \\
mean & $\mathbf{0 , 8 4}$ & $\mathbf{0 , 7}$ & $\mathbf{1 , 4 4}$ & $\mathbf{1 , 7 2}$ & $\mathbf{1 , 2 1}$ & $\mathbf{2 6 0}$ & $\mathbf{2 4 5}$ & $\mathbf{2 6 6}$ & $\mathbf{7 7 1}$ & $\mathbf{6 5}$ & $\mathbf{6 3 , 5}$ & $\mathbf{5 9}$ \\
\hline
\end{tabular}

PT= Paratype; LT= Lectotype; AM=anteromedial setae (trichobothridial); $\mathrm{SS}=$ posteromedial setae (trichobothridial); $\mathrm{AL}=$ anterolateral setae; $\mathrm{PL}=$ posterolateral setae; $\mathrm{AA}=$ distance between the insertion of setae $\mathrm{AM} ; \mathrm{SB}=$ distance between the insertion of setae $\mathrm{S} ; \mathrm{AW}=$ distance between the insertion of setae $\mathrm{AL} ; \mathrm{PW}=$ distance between the insertion of setae $\mathrm{PL} ; \mathrm{ASB}=$ distance between the anterior margin of the prodorsal sclerite and the base of botrichial setae $\mathrm{S} ; \mathrm{PDB}=$ distance between the posterior margin of the prodorsal sclerite and the base of botrichial setae $\mathrm{S} ; \mathrm{SD}=$ length of the prodorsal sclerite; $\mathrm{SD}=\mathrm{ASB}+\mathrm{PSB} ; \mathrm{AP}=$ distance between the insertion of setae $\mathrm{AL}$ and $\mathrm{PL}$; pa=legI lengh; pm=leg II lengh; pp= leg III lengh; Ip=pa+pm+pp; T1-3= lenght of tarsus I, II and III. 


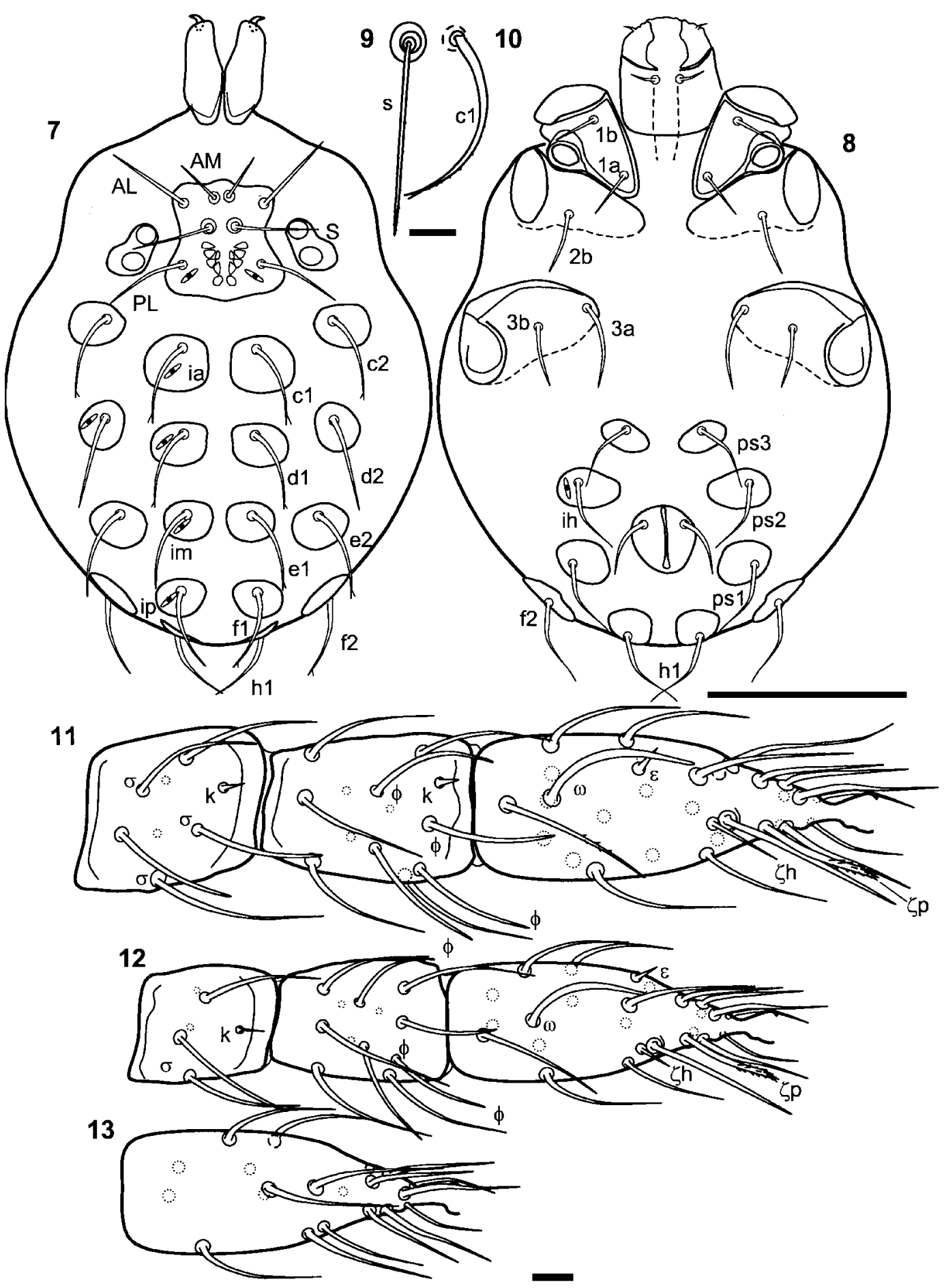

FIGURES 7-13. Polydiscia deuterosminthurus sp. nov. 7. Body dorsal view. 8. Body ventral view. 9. S seta. 10. Dorsal seta c1. 11. Genua, tibia and tarsus of left leg I: dorsal view. 12. Genua, tibia and tarsus of left leg II: dorsal view. 13. Tarsus of left leg III: dorsal view. (Bar 7 and 8: $100 \mu \mathrm{m} ; 9$ to $13: 10 \mu \mathrm{m})$. 
Discussion. We had the opportunity to study a lectotype of the type species (specimen also studied by Vercammen-Grandjean in his paper of 1972). However, it shows evidence of having been manipulated and actually lacks both pairs of trichobothria. Our observations expose errors of observation or interpretation of several characteristics given by Vercammen-Grandjean for the species. The missing setae enable us to confirm an important characteristic of this species and we were forced to follow Vercammen-Grandjean's description and measurements of these setae.

Although Vercammen-Grandjean (1972) indicate a palpalsetal formula for P. squamata of (B)-(B)-(N).N.N, the type studied shows a formula similar to that of P. deuterosminthurus sp. nov. and on the coxae, all the setae were described as nude (they are clearly branched setae). In leg I, P. squamata has two genualae $\sigma$ and although VercammenGrandjean (1972) indicate two tibialae $\phi$ and 21 branched setae in the tarsus, the type specimen has four $\phi$ on tibia and $25 \mathrm{~B}$ and $\xi \mathrm{p}$ with setules in the tarsus.

P. deuterosminthurus sp. nov. can be separated from P. squamata Methlagl, 1928 by the following characteristics: (1) besides length difference of the prodorsal sclerite (AD), AA, PW, AP (see table I), in $P$. deuterosminthurus sp. nov. setae $\mathrm{PL}>\mathrm{S} \geq \mathrm{AL}>\mathrm{AM}$ versus $\mathrm{PL}<\mathrm{S}>\mathrm{AL}<\mathrm{AM}$. (Vercammen-Grandjean, 1972) in P. squamata; (2) shorter length of legs I-III in P. deuterosminthurus sp. nov., Ip $=710(697,682-710,3)$ versus Ip $=771$ (742-800, 2) in P. squamata; (3) tarsus II shorter in P. deuterosminthurus sp. nov., T2 $=57$ (56, 56$57,3)$ versus $\mathrm{T} 2=64(63-64,2)$ in $P$. squamata; (4) leg I with $3 \sigma$ in $P$. deuterosminthurus sp. nov. versus $2 \sigma$ in $P$. squamata.

The specimens obtained by Methlagl of $P$. squamata were collected free-living in vacant lot and this species's host is yet unknown.

Biology. With the capture of the larvae of $P$. deuterosminthurus sp. nov. parasitizing D. bisetosus sp. nov., the first host association of this genus is established.

Concerning the location of the mite on the host, the majority were found on the dorsal body surface, with the gnathosoma embedded in the posterior area of the articulation between head and prothorax (Figure 1). This location agrees with that seen by Greenslade \& Southcott (1980) for the erythraeid parasites from Corynephoria observed in Australia.

Although Greenslade \& Southcott (1980) wrote that "parasitism on the Collembola is unknown although animals seemed moved normally and on microscopic examination appear unaffected', we observe that the physiological effect on the host may be lethal since the infested hosts show a high degree of dehydration, with a lack of antennal turgescence in such a way that these appendices rest folded back. The mites are easily separated from the host and although light scars were observed, the degree of injury to the host cuticle was not great.

When parasitic mite densities are high, the effect on collembolan populations could be significant (Greenslade \& Southcott, 1980). In our population the mean intensity of infestation is 1, although several Collembola bear two mites. The prevalence, that is, number of individuals of a host species infested divided by the number of hosts examined (Margolis 
et al, 1982), is around $10 \%$. The relationship between parasite and host size is approximately 3:1.

P. deuterosminthurus sp. nov. seems to have an annual cycle, with a larval parasitic instar during the spring. It shows a high specificity for the Collembola species later described, since the mite has been not found on other Collembola and arthropods living together with the parasite species.

The sampling was extended over a period of several weeks after the first capture (May 1999). Adult specimens of the mites were never found. D. bisetosus sp. nov. and larvae of P. deuterosminthurus sp. nov. were not found on plants after the first fortnight of June, the moment of the year when temperatures increase and the environmental humidity does not allow the presence of Symphypleona on the vegetation. Further specimens of D. bisetosus sp. nov. and P. deuterosminthurus sp. nov. were not captured until May of 2000 and 2001. Attempts to rear the mite in the laboratory in order to follow the postlarval instars failed.

\section{Deuterosminthurus bisetosus sp. nov. (Figs 14-42)}

Type-locality: SPAIN, Navarra, Otazu, (UTM co-ordinates 30TWN993375).

Type-specimens: Holotype (female) and allotype (male) ex Genista hispanica L. MZNA00309-01, 26.V.1999, E. Baquero and L. Hernández leg.; paratypes: two specimens on slide MZNA00309-02, eight specimens on SEM stub and six in ethyl alcohol.

Additional material: SPAIN, Navarra, Otazu,: MZNA00310 (28.V.1999, 3 on slide, 12 on SEM stub, 32 in ethyl alcohol), MZNA00353 (9.V.2000, 31 in ethyl alcohol), MZNA00362 (26.V.2000, 69 in ethyl alcohol), MZNA00365 (8.VI.2000, 4 in ethyl alcohol), MZNA00389 (30.V.2001, 2 on SEM stub, 26 in ethyl alcohol), E. Baquero and R. Jordana leg. Vedado de Eguaras, (R. Jordana and E. Baquero leg.): MZNA00349 (8.V.2000, 2 on slide, 2 on SEM stub, 15 in ethyl alcohol). El Yugo, (R. Jordana and E. Baquero leg.): MZNA00390 (6.VI.2001, 3 in ethyl alcohol). Huesca, Canal Roya, Pyrenees (30TYN0742, R. Jordana leg.): MZNA00395 (1.7.2001, 11 in ethyl alcohol). Astún, Pyrenees (30TYN0441, R. Jordana leg.): MZNA00396 (2.7.2001, 27 in ethyl alcohol), MZNA00400 (10.7.2001, 13 in ethyl alcohol). Málaga, Benalmádena, (30SUF5951, A. Altuna leg.): MZNA00408, MZNA00410 and MZNA00412 (17.VII.2001, 108 in ethyl alcohol). FRANCE, Somport, Pyrenees (30TXN9843, R. Jordana leg.): MZNA00394 (29.6.2001, 1 in ethyl alcohol).

Material deposited: MZUN (Museum of Zoology, University of Navarra).

Description (Figures 1, 14-42). Adults size. Female: 0.75-1.4 mm $(n=4)$; male: 0.85 $\mathrm{mm}$ (Figure 14).

Colour. Live specimens show a pale yellowish general appearance with brown-violet patches around the trichobothria insertions (A, B and C) as the most characteristic feature. They are variable from pale brown-violet to red patches over the great abdomen (Figures 36-42). Specimens of this species collected from Pyrenees, Bardenas Reales (Southern 
Navarra) (Figure 40) and Málaga (Southern Spain) (Figure 41) show a great variation of the pattern. This pattern includes specimens which are completely yellow (Otazu) (Figures 39 and 42) to specimens with a characteristic pattern with a yellow ' $\mathrm{V}$ ' shaped form over the dark red on the last half of the great abdomen (Figure 38, 40 and 41). This pattern appears vague in other specimens including those of type locality.
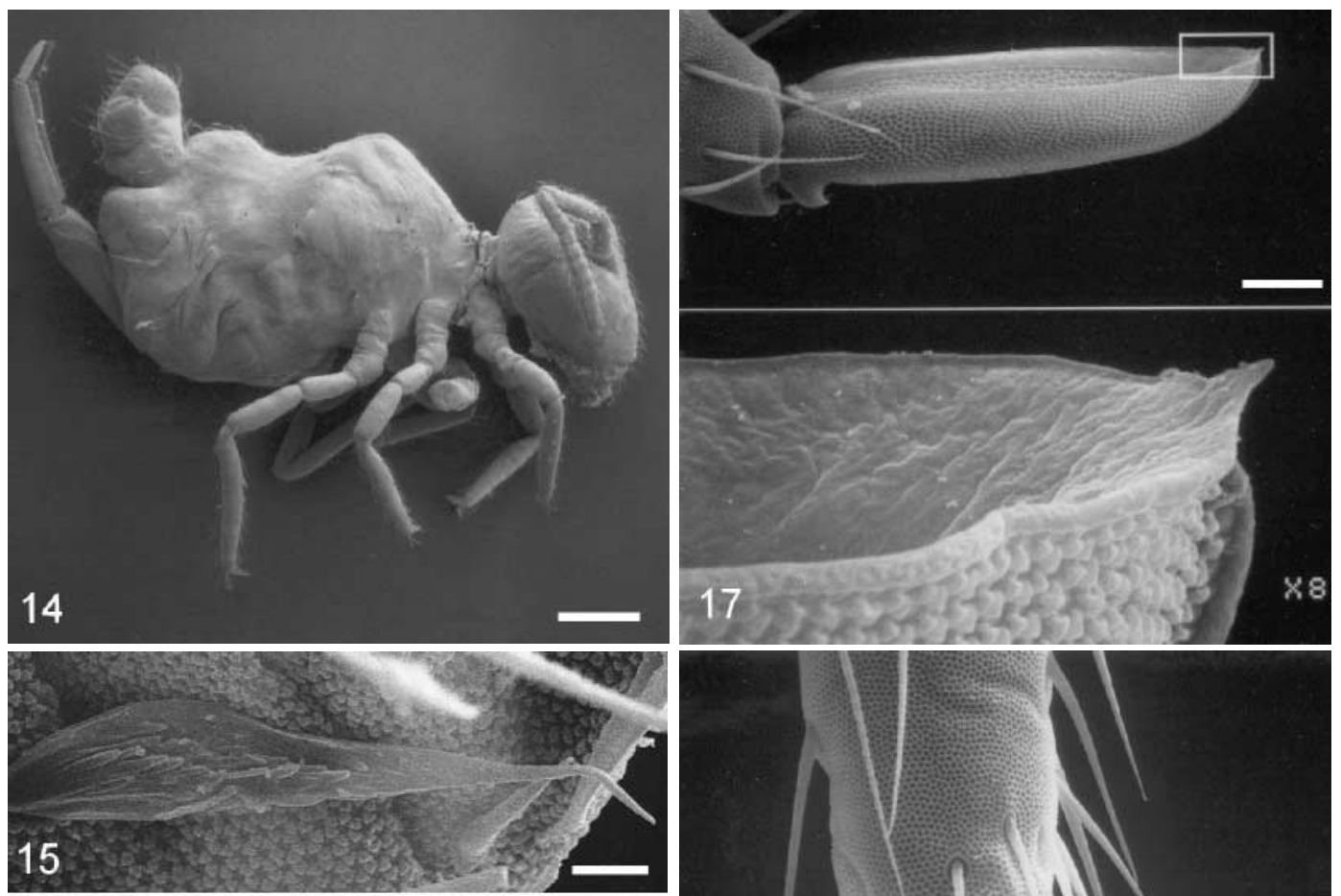

\section{5}
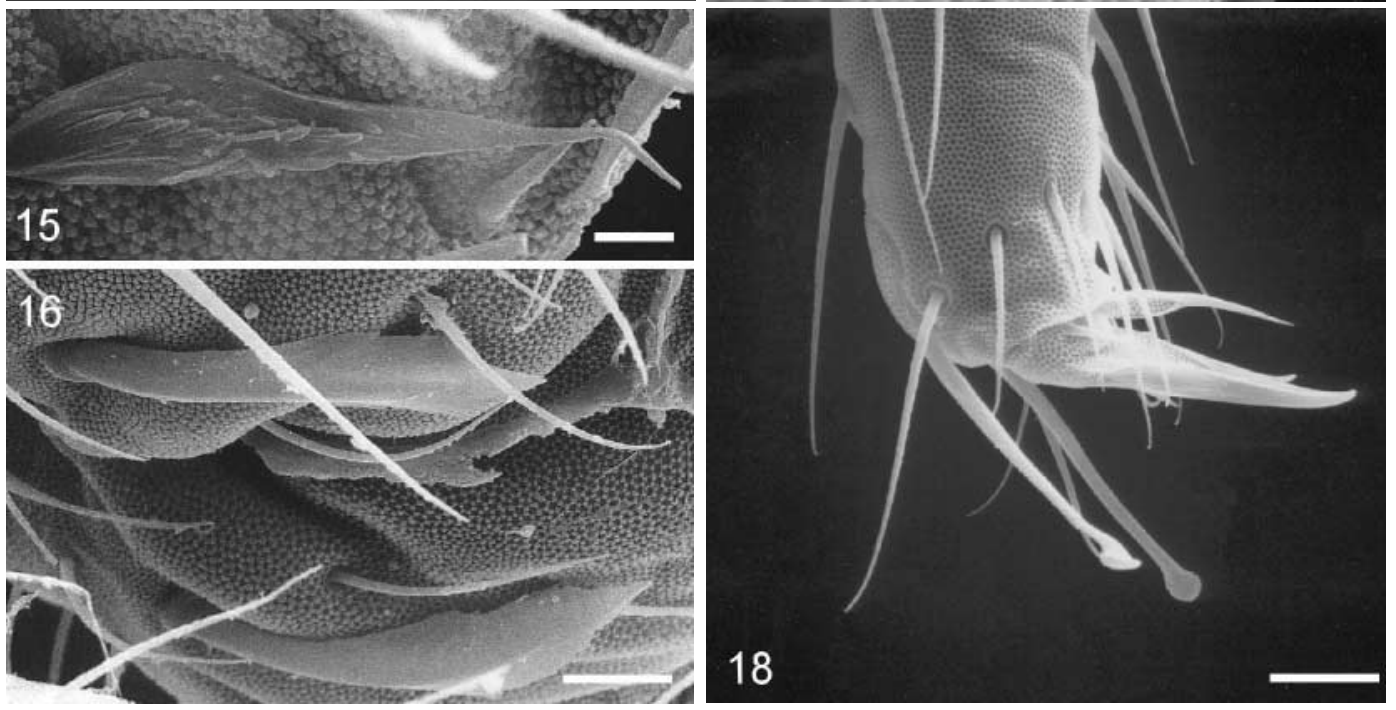

FIGURES 14-18. Deuterosminthurus bisetosus sp. nov. 14. Habitus of a female (Bar: $100 \mu \mathrm{m}) .15$. Ja seta of leg I (Bar: $2 \mu \mathrm{m})$. 16. Anal appendage of female (Bar: $10 \mu \mathrm{m}$ ). 17. Mucro and detail of its tip (Bar: $10 \mu \mathrm{m})$. 18. Distal part of leg III (Bar: $10 \mu \mathrm{m})$ 


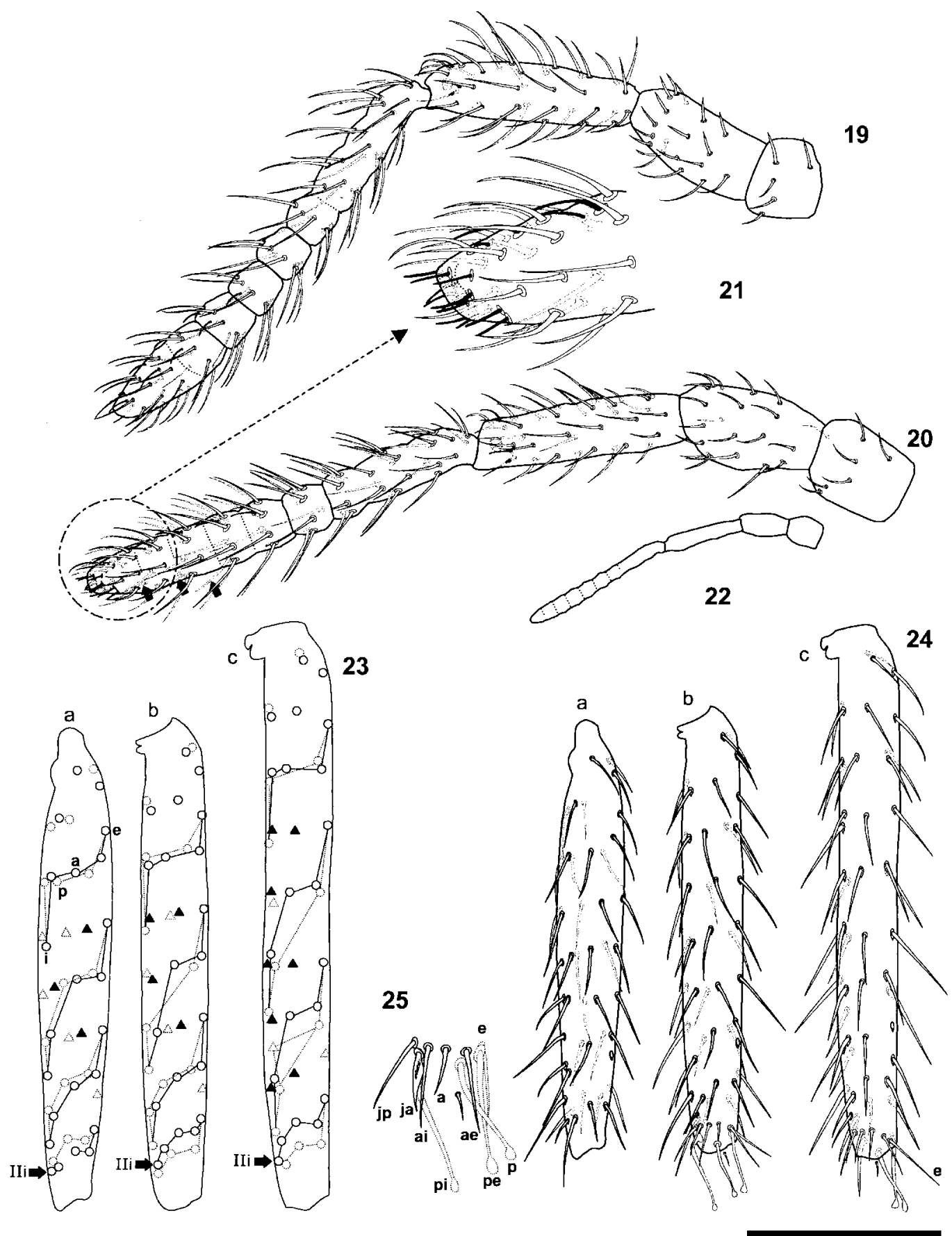


Antennae (Figures 19-22). Antennal ratios: in female, ant. I/II/III/IV $=1 / 1.6 / 2.3 / 4.4$ and antennal segment/cephalic diagonal $=1.7$; in male, ant. I/II/III/IV $=1 / 1.5 / 2.8 / 6$ and antennal segment/cephalic diagonal $=1.3$. Male antennal segment II with acanthoids setae in three whorls: $2+2+3$ and two more on antennal segment I. Additional posteroventral setae of antennal segment IV (ventral sensilla for some authors) on $\mathrm{d} 3, \mathrm{~d} 4$ and $\mathrm{d} 5$ of male and female (Figure 20, arrows); sensorial setae of male on d1 (0-1), d2-3 (1-2), d4, d5 and d6 (2); female: d2-d6 (2) (Figures 30-31). There are 11-12 whorls of structural setae. The antennal segments have a variable level of ringing in different specimens, higher in the male. Sensory organ of antennal segment III with three accessory sensillae, two long and one short.

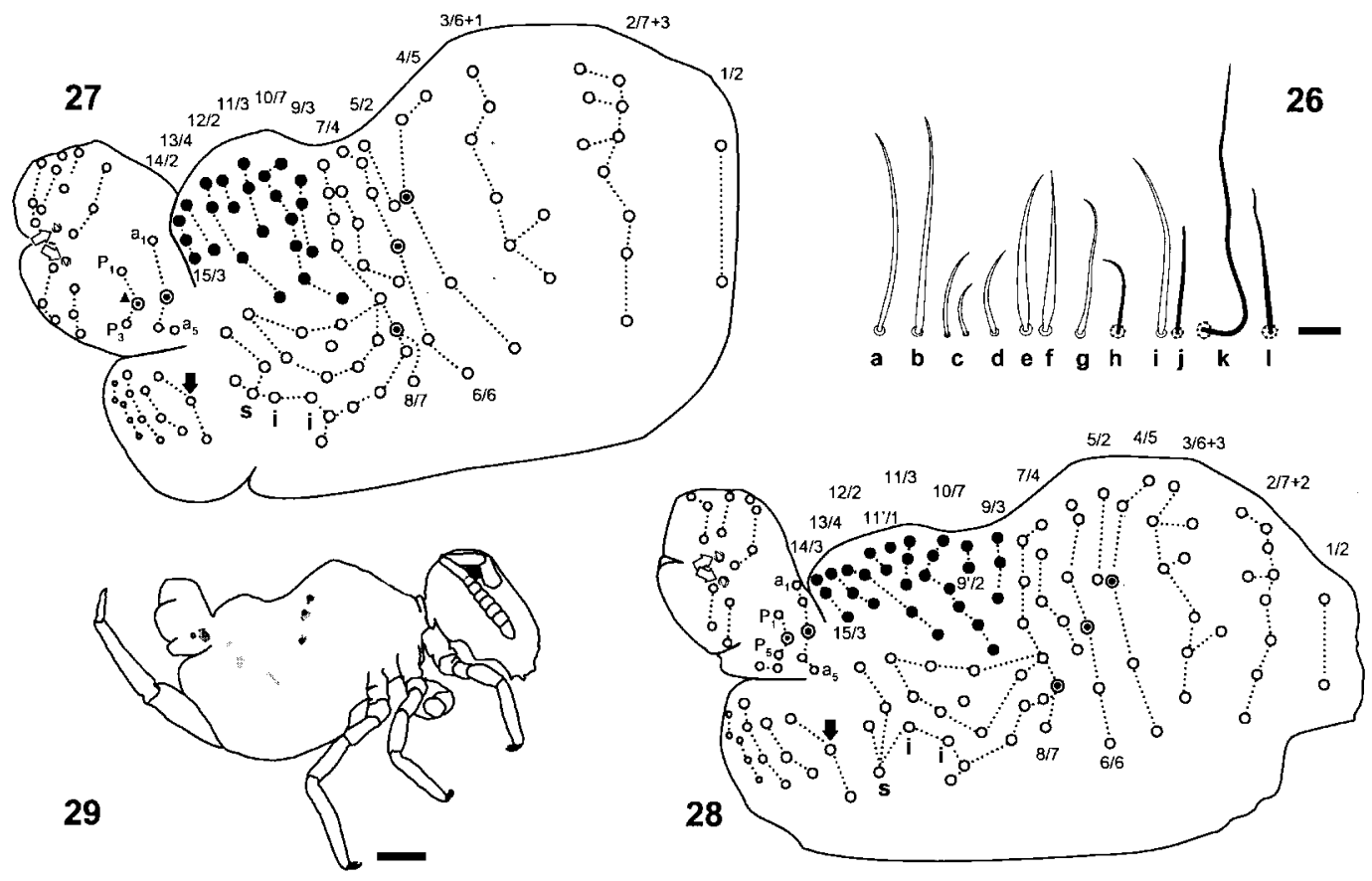

FIGURES 26-29. Deuterosminthurus bisetosus sp. nov. 26. Some setae of the body. a: row 15 of great abdomen of male; b: row 15 of great abdomen of female; c: row 10-11 of great abdomen of male; d: row 10 of great abdomen of female; e: seta ventrolateral lightly swollen, posterior to lateral sensilla (arrow in Figure 27), male; f: seta ventrolateral lightly swollen, posterior to lateral sensilla of female; g: second 'i' seta (contiguous to lateral sensilla 's') of male; h: lateral sensilla 's' of male; i: second ' $i$ ' seta (contiguous to lateral sensilla 's') of female; $j$ : lateral sensilla 's' of female; $\mathrm{k}$ : trichobothria D of female; 1: trichobothria E of female (Bar: $10 \mu \mathrm{m})$. 27. Chaetotaxy of great and small abdomen of male (nomenclature modified from Betsch \& Bretfeld, 1991). The hollow arrows points to the oval organs. 28. Chaetotaxy of great and small abdomen of female. The black arrow points to the setae drawn in $26 f$. The hollow arrows points to the oval organs. 29. Lateral colour pattern of a semi-pale specimen from Otazu (Navarra) (Bar: $10 \mu \mathrm{m}$ ) 
Head. Eyes: 8+8; eyepatch with two setae. Cephalic setae: mesochaetae, with setae head-back with $1+1$ oval organs (Figure 33 ).

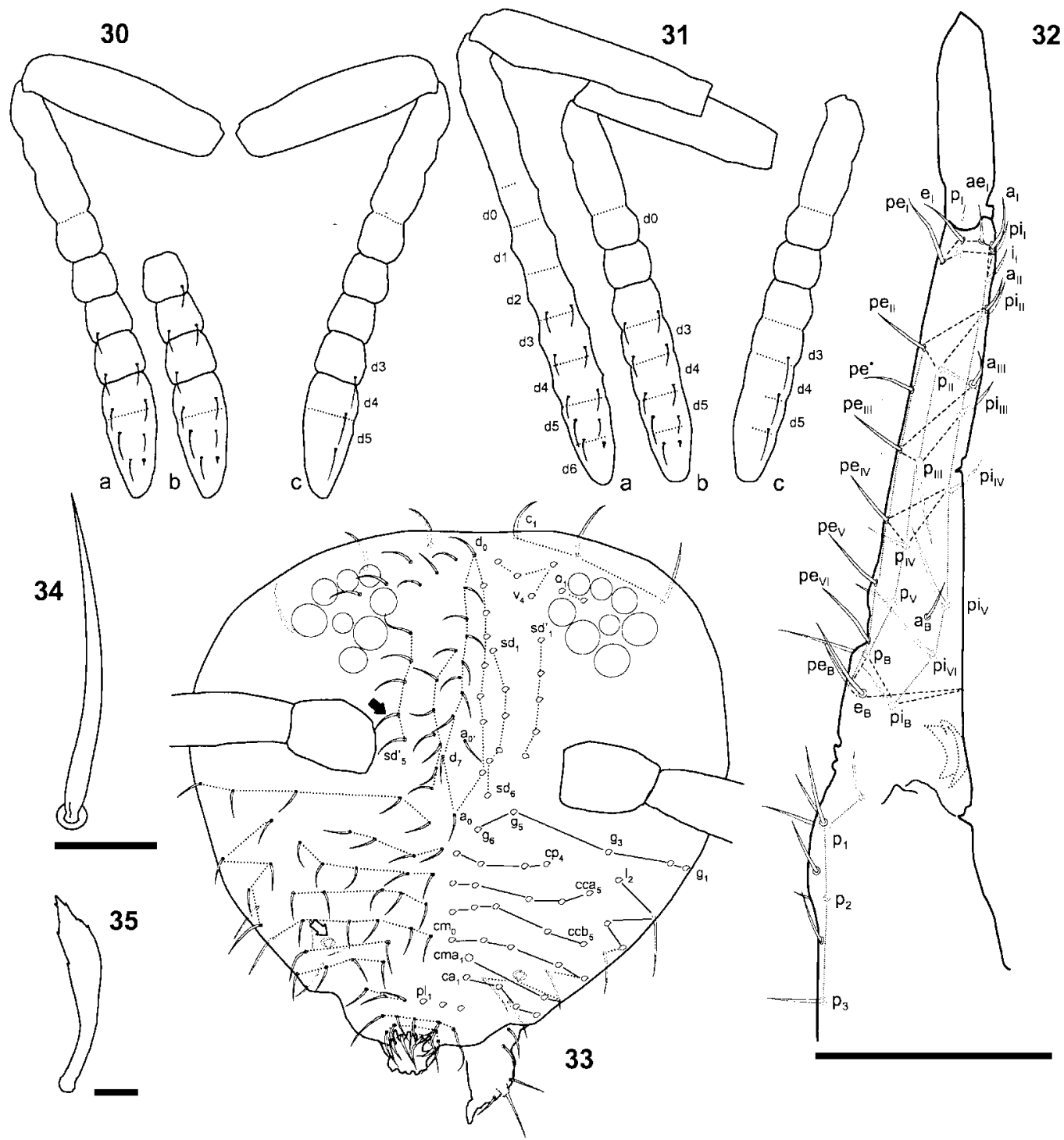

FIGURES 30-35. Deuterosminthurus bisetosus sp. nov. 30. Antennae of male. 31. Antennae of female ( $\mathrm{a}$ and $\mathrm{b}$ with sensillae of dorsal side; $\mathrm{c}$ with special setae of posteroventral side). 32. Chaetotaxy of the furcula (according to Nayrolles's 1990 nomenclature) (Bar: 0.1 mm). 33. Chaetotaxy of the head. The white arrow points to the oval organ (abbreviations: c, cervical; v, vertical; o, ocular; d, dorsal; a, anterior; sd, sub-dorsal; g, genal; cp, clipeal posterior; cc, clipeal central; cm, clipeal medial; cma, clipeal medial anterior; ca, clipeal anterior; pl, pre-labral). 34. Seta Sd'4 (black arrow in D) (Bar: $0.01 \mathrm{~mm})$. 35. Female anal appendage (Bar: $10 \mu \mathrm{m}$ ) 

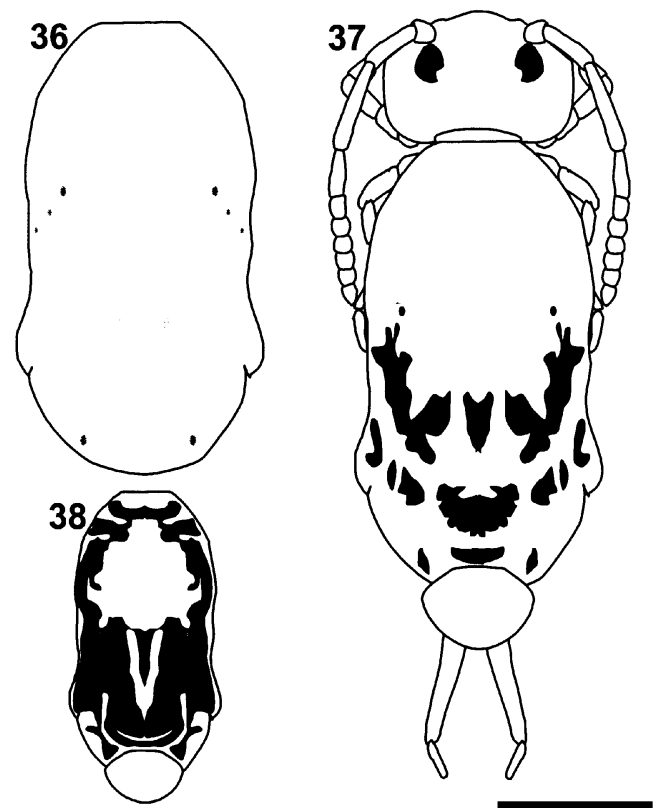

FIGURES 36-38. Deuterosminthurus bisetosus sp. nov. 36. Colour pattern of a completely pale specimen from Otazu (central Navarra). 37. Generalised coloration of the species, with pale brown-violet patches. 38. Orange-red coloured specimen from 'Vedado de Egüaras' (southern Navarra). In all cases the intensity of the colouration is variable (Bar: 0,25 $\mathrm{mm}$ ).
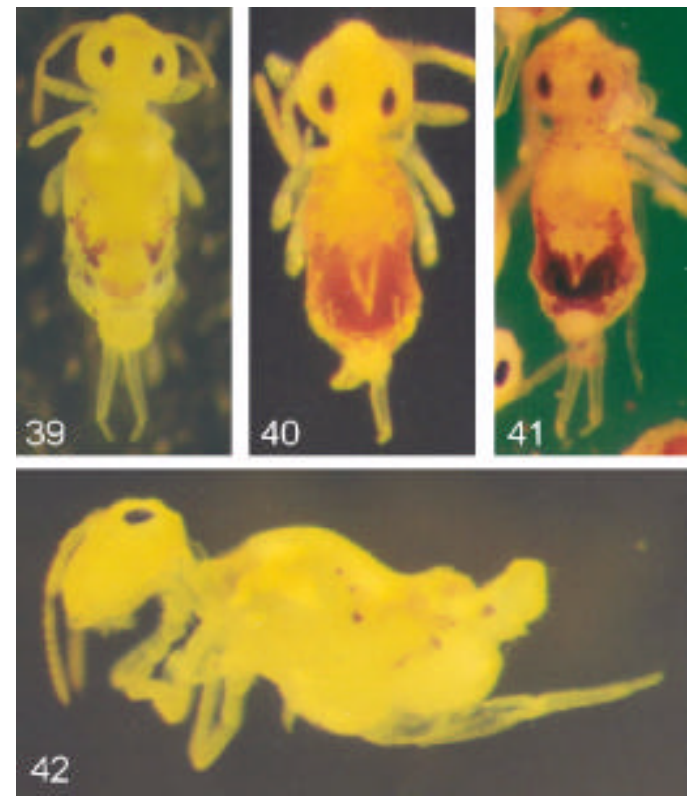

FIGURES 39-42. Deuterosminthurus bisetosus sp. nov. 39. Colour pattern of a pale specimen from Otazu (north of Navarra). 40. Red coloured specimen from 'Vedado de Egüaras' (south of Navarra). 41. Dark pattern of a specimen from Benalmádena (Málaga, south of Iberian Peninsula). 42. Lateral view of a specimen from Otazu showing the dark insertion area of the trichobothria.

Great abdomen. Trichobothria A, B, and C in a linear pattern. Dorsal setae not different between sexes, and last row longer (Figures $26 \mathrm{a}-\mathrm{b}$ ). The number and position of the setae of the great and small abdomen segments of male and female are schematised in Figures 27 and 28. There are two 'i' setae before the sensilla 's' on lateral of the great abdomen (Figures 27-28). The group of setae on posterior dorsal great abdomen (rows 9 to 15) includes 28 setae in the female and 24 in the male. There are three long and lightly swollen setae in the first row behind the sensilla and below the small abdomen (Figures 26e and 26f). Behind this row there are four more rows with 3, 3-4, 2-3 and 2 setae, respectively.

Legs. Tibiotarsus with oval organ present on the three legs (Figures 23-24). External setae on tibiotarsus III 1.5x longer than diameter (Figure 24). Pretarsus characteristic of the genus, with seta Ja winged (Figures 15, 25). Spatulated setae formula of whorl I: 3-3-2 in legs I, II and III, respectively. Claws with large inner tooth (apomorphic character) and other proximal anterior and lateral; empodia without terminal filament (Figure 18).

Ventral tube. Apical flaps with one pair of setae and corpus without seta.

Retinaculum. Tridentate $(2+1)$ and with three apical setae on the corpus. 
Furcula. Chaetotaxy as in Figure 32. Length of the mucro: 50-65 $\mu \mathrm{m}$ (Figure 17).

Small abdomen. The males lack the $\mathrm{a}_{2}$ seta on the first row of the small abdomen.

There is a small sensilla just behind trichobothria E. Male genital papilla similar in size to ventral anal valves. Two oval organs on each side (hollow arrows in Figures 27-28). Length of the anal appendages: $48 \mu \mathrm{m}$. (Figures 16 and 35).

Taxonomic discussion. The specific diagnostic characteristics of $D$. bisetosus $\mathrm{sp}$. nov. are: two ' $i$ ' setae between ' $s$ ' sensilla on lateral of the great abdomen and the fourth setae of row posterior to trichobothria $\mathrm{C}$ (Figures 27-28); the characteristic colouring observed in specimens from localities of the Iberian Peninsula (Navarra and Málaga), even from localities nearly $2000 \mathrm{~m}$ high in the Pyrenees (Astún). Although D. bisetosus sp. nov. shares with Navarrella apicalis Bretfeld and Arbea, 2000 the presence of two 'i' setae, have the remain characters of the genus Deuterosminthurus. We have seen a cleared specimen, identified as Bourletiella pallipes (Bourlet, 1843) (Gisin collection, MHNG), possibly a $D$. bisetosus sp. nov. (dark facies) from the northern Pyrenees. A similar range of colouring is observed in D. pallipes, with D. repanda as the pale facies with red patches. Any specimen of $D$. bisetosus sp. nov. with general dark blue pattern, typical for D. pallipes, has not been found within the captured populations. The dark form of D. pallipes has only an 'i' seta (Bretfeld, personal communication).

$N$. apicalis can be distinguished from $D$. bisetosus sp. nov. because seta IIi is present only on leg III, the special ventral setae (sensillae for some authors) of the antennal segment IV are on d2, d4 and d5 segments, and four setae are present on retinaculum (Bretfeld \& Arbea, 2000).

In the collection of the Museum of Zoology of the University of Navarra there is a specimen with asymmetry in the special ventral setae of the antennal IV (d2, d4, d5/d3, d4, d5) and with the terminal setae of the small abdomen of the male very similar to those of D. sulphureus.

Specimens of other species have been compared with the new species: B. pallipes (Stach's collection, PAS), B. repanda Âgren, 1903 (Stach's collection, Szeptycki leg. and Weiner leg. specimens from PAS and six specimens from MHNG), B. mixta Gisin, 1957 and B. flava (holotype male and paratypes females from Vessi, Gisin collection, MHNG). All of these species have only an ' $i$ ' seta and a pattern of colouring different to those of the new species.

\section{Acknowledgements}

We wish to thank Prof. Wolfgang Schedl (Institut für Zoologie, Innsbruck) for the loan of the Type specimen of Polydiscia squamata for study, Wanda Weiner (PAS: Polish Academy of Sciences, Krakow) and Peter Schwendinger (MHNG: Muséum d'Histoire naturelle, Ville de Genève) for the loan of specimens of Bourletiella spp., and Dr. Cal Wel- 

vices) for helpful discussions on the problem of the identification of adult specimens of Prostigmata and questions about their culture. We thank Dr. G. Bretfeld for confirming us the presence of a single i setae on the great abdominal of D. pallipes. We thank the reviewers of this paper for their helpful suggestions. Part of this work was supported by the Project CICYT IN92-0225, Infrastructures of Investigation and 'Fauna Ibérica VI (REN2000-1602/GLO)' Ministry of Culture and Technology, Spain.

\section{References}

Betsch, J.M. \& Bretfeld, G. (1991) A proposal for a standard system of chaetotaxic nomenclature in the Symphypleona (Insecta: Collembola). In: Veeresh, G.K., Rajagopal \& D., Viraktamath, C.A. (Ed). Advances in management conservation of soil fauna. Universal Book Services, pp. 31-38.

Bretfeld, G. \& Arbea, J.I. (2000) Navarrella apicalis, a new genus and species of the monophylum Bourletiellidae from northern Spain (Insecta, Collembola, Bourletiellidae). Senckenbergiana biologica, 80, 127-133.

Greenslade, P. \& Southcott, R.V. (1980) Parasitic mites on sminthurid Collembola in Australia. Entomologist's Monthly Magazine, 116, 85-87.

Haitlinger, R. (1991) List of mites occurring on insects in Poland. Wiadomosci Parazytologiczne, 37, 85-90.

Handschin, E. (1926) Collembola-Springschwänze, in Schulze. Biologie der Tiere Deutchlands, Berlin, 25, 7-56.

Jordana, R., Arbea, J.I., Simón, C. \& Luciáñez, M.J. (1997) Collembola Poduromorpha. In: Ramos, M.A. et al. (Ed) Fauna Ibérica, Vol. 8, Museo Nacional de Ciencias Naturales, Consejo Superior de Investigaciones Científicas, Madrid, $807 \mathrm{pp}$.

Methlagl, A. (1928) Über die Trombidiose in den Österreichischen Alpenländen. Denkschriften Akademie der Wissenschaften, 101, 213-250.

Margolis, L., Esche, G.W., Holmes, J.C., Kuris, A.M. \& Schad, G.A. (1982) The use of ecological terms in parasitology (report of an ad hoc Committee of the American Society of Parasitologists). Journal of Parasitology, 68, 131-133.

Nayrolles, P. (1987) Chetotaxie tibiotarsale des Collemboles symphypleones. Travaux du Laboratoire d'Ecobiologie des Arthropodes Edaphiques, 5, 1-19.

Nayrolles, P. (1990) Chetotaxie furcale des Collemboles symphypleones. Travaux du Laboratoire d'Ecobiologie des Arthropodes Edaphiques, 6, 27-50.

Saito, Y. \& Osakabe, M.H. (1992) A New Fixation Method for Preparing Mite Specimens for Optical and SEM Microscopic Observations. Applied Entomology and Zoology, 27, 427-436.

Vercammen-Grandjean, P.H. (1972) Revision of Womersley's Apoloniinae (Acarina, Leeuwenhoekidae) from the asiatic-pacific region. Folia Parasitologica, 19, 227-252.

Waldorf, E. (1974) Notes on Sminthurus fuscus (L.) and its phoretic acari. Revue d'Écologie et de Biologie du Sol, 11, 363-365.

Welbourn, W.C. \& Young, O.P. (1987) New genus and species of Erythraeinae (Acari: Erythraeidae) from Mississippi with a key to the genera of North American Erythraeidae. Annals of the Entomological Society of America, 80, 230-242. 